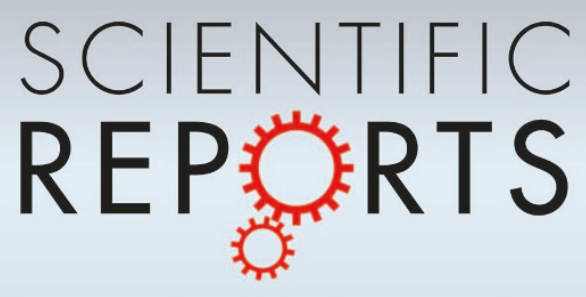

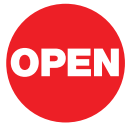

SUBJECT AREAS:

ECOSYSTEM SERVICES

ENVIRONMENTAL SCIENCES

BIOGEOCHEMISTRY

URBAN ECOLOGY

Received

1 August 2012

Accepted

13 November 2012

Published

12 December 2012

Correspondence and requests for materials should be addressed to J.L.E. (j.edmondson@ sheffield.ac.uk)

\section{Organic carbon hidden in urban} ecosystems

\author{
Jill L. Edmondson' ', Zoe G. Davies², Nicola McHugh', Kevin J. Gaston³ \& Jonathan R. Leake'
}

\begin{abstract}
'Department of Animal and Plant Sciences, University of Sheffield, Sheffield S10 2TN, U.K., ${ }^{2}$ Durrell Institute of Conservation and Ecology (DICE), University of Kent, Canterbury, Kent CT2 7NR, U.K., ${ }^{3}$ Environment and Sustainability Institute, University of Exeter, Penryn, Cornwall TR 10 9EZ, U.K.
\end{abstract}

Urbanization is widely presumed to degrade ecosystem services, but empirical evidence is now challenging these assumptions. We report the first city-wide organic carbon (OC) budget for vegetation and soils, including under impervious surfaces. Urban soil OC storage was significantly greater than in regional agricultural land at equivalent soil depths, however there was no significant difference in storage between soils sampled beneath urban greenspaces and impervious surfaces, at equivalent depths. For a typical U.K. city, total OC storage was $17.6 \mathrm{~kg} \mathrm{~m}^{-2}$ across the entire urban area (assuming $0 \mathrm{~kg} \mathrm{~m}^{-2}$ under $15 \%$ of land covered by buildings). The majority of OC $(82 \%)$ was held in soils, with $13 \%$ found under impervious surfaces, and $18 \%$ stored in vegetation. We reveal that assumptions underpinning current national estimates of ecosystem OC stocks, as required by Kyoto Protocol signatories, are not robust and are likely to have seriously underestimated the contributions of urban areas.

\section{$\Lambda$} ccurate assessments of ecosystem carbon stocks are crucial to understand anthropogenic changes to the global carbon cycle, and to guide effective management ${ }^{1-3}$. Soil and vegetation together store $2110 \mathrm{Pg}$ of organic carbon (OC), which is nearly three times more than atmospheric $\mathrm{CO}_{2}$, with soils holding $74 \%$ of this total ${ }^{4,5}$. There has been a substantial historical decline in soil and vegetation OC of approximately $156 \mathrm{Pg}^{6}$, driven predominantly by shifts in land-use from natural and semi-natural to agricultural ecosystems and disturbed landscapes ${ }^{2,6-8}$. Although the shift to intensive agriculture has been the primary driver of land-use change, at present more than half the global human population resides in cities and towns, a figure projected to rise to $70 \%$ by $2050^{9}$. As a consequence, urban areas are increasing in extent at a greater pace than any other land-use type $\mathrm{e}^{10-13}$. Indeed, in both Europe and the U.S.A. increases in the areal extent of urban areas have outpaced growth in the urban population ${ }^{14,15}$. The resulting impacts on ecosystem services, including soil and vegetation OC stocks remain poorly characterised.

In densely urbanized areas such as Europe, a region where planning constraints have led to a tendency for cities and towns to become more dense rather than to spraw ${ }^{16,17}$, urban land is estimated to cover $9 \%$ of the continent ${ }^{18}$ and grey infrastructure (buildings, roads and other sealed surfaces) often covers more than $50 \%$ of city area ${ }^{19}$. In fact, grey infrastructure is estimated to cover nearly $580,000 \mathrm{~km}^{2}$ globally, an area exceeding the size of France ${ }^{20}$. However, the impact of this on national ecosystem OC inventories has not been established. In the U.K., a country characterised by a high proportion of built over land ${ }^{21}$, approximately $3 \%$ of the terrestrial surface is covered by grey infrastructure $\left(7576 \mathrm{~km}^{2}\right)$ which far exceeds the equivalent proportion of land covered by impervious surfaces and buildings in the U.S.A. ${ }^{20}$.

To date, the total quantity of $\mathrm{OC}$ stored in urban soils (under both impervious surfaces and greenspaces), together with that in above-ground vegetation, has never been systematically measured. This highlights a major gap in understanding of this crucial ecosystem service, for which Kyoto protocol signatories are required to provide accurate inventories in national estimates of OC storage. To date, urban areas have either been excluded from such inventories ${ }^{22}$, or their contributions estimated by highly conservative and untested assumptions ${ }^{3,23-25}$. However, there is increasing evidence that urban ecosystems may be able to store considerable amounts of OC in their vegetation and soils ${ }^{26-33}$. The majority of this work has focused on a limited number of samples in the U.S.A., where cities tend to sprawl over large areas, and historical, land-use and climatic factors are likely to result in differences in OC storage compared to other regions such as Western Europe, where cities and towns are often longer-established and more compact ${ }^{16}$. Furthermore, only one U.S.A. based study, has directly measured soil OC storage beneath impervious surface, analyzing OC concentrations beneath pavements in New York City ${ }^{33}$. The quantities under other impervious surfaces and in other regions remain unstudied. 


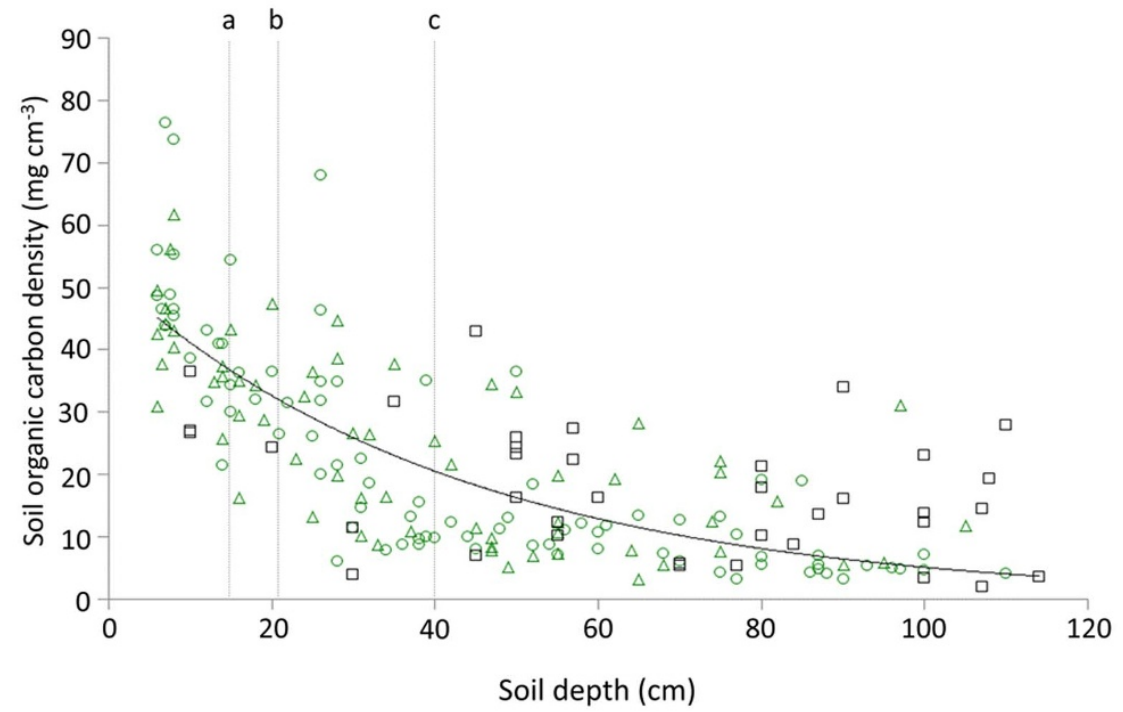

Figure $1 \mid$ The relationship between soil organic carbon density $\left(\mathrm{mg} \mathrm{cm}^{-3}\right)$ and depth in urban soils. Capped soils represented by open square data points $(\square)$; herbaceous soils represented by open circular data points $(\bigcirc)$, and; tree and shrub soils represented by open triangular data points $(\Delta)$. The vertical lines indicate the depth below which the fitted curve was applied to (a) areas of non-vehicle load bearing impervious surface, (b) urban greenspaces (c) vehicle-load bearing impervious surface.

In this paper, we investigate the contribution of urban areas to ecosystem OC stocks using a mid-sized U.K. city (Leicester). We provide a first assessment of the impact of soil capping, across a range of types of impervious surface, including pavements, footpaths, patios and roads, on ecosystem OC storage (to $100 \mathrm{~cm}$ depth). In comparing soil OC storage density $\left(\mathrm{mg} \mathrm{cm}^{-3}\right)$ beneath impervious surfaces with that below urban greenspaces and soils sampled from the agricultural hinterland of the city, we are able directly to assess the impact of an entire city on soil OC stocks. Furthermore, we combine soil and above-ground vegetation OC stocks ${ }^{32}$ to construct the first city-wide ecosystem OC budget from the tree tops down to $100 \mathrm{~cm}$ soil depth. The research presented highlights the need for a radical reappraisal of the contribution of urban ecosystems to national OC inventories, and has far-reaching implications for land-use change and planning policy, particularly in densely urbanized regions globally.

\section{Results}

Soil $\mathrm{OC}$ density in urban areas to $100 \mathrm{~cm}$ depth: greenspace versus capped soils. There was no significant difference in soil OC density $\left(\mathrm{mg} \mathrm{cm}^{-3}\right)$ at equivalent depths between the capped, herbaceous and tree \& shrub land-cover classes (Fig. 1, Table 1); however, there was a significant effect of the covariate soil depth on OC density (Table 1). The relationship between urban soil OC density (beneath both impervious surfaces and greenspace) and depth was described by a highly significant negative exponential function $\left(R^{2}=57 \%, F_{(1,184)}\right.$ $=243.8, p<0.001, \mathrm{y}=51.910( \pm 2.492$ S.E. $\left.) \mathrm{e}^{-0.0232( \pm 0.002 \text { S.E. }) \times}\right)$ (Fig. 1). This relationship between soil OC density $\left(\mathrm{mg} \mathrm{cm}^{-3}\right)$ and depth, equates to a total storage value of $20.2 \mathrm{~kg} \mathrm{OC} \mathrm{m^{-2 }}$
(95\% confidence intervals; $18.3-22.1 \mathrm{~kg} \mathrm{~m}^{-2}$ ) between $0-100 \mathrm{~cm}$ depth.

Soil OC storage beneath impervious surfaces was limited by the depth of excavation for the capping surface (Fig. 1), and was $6.7 \mathrm{~kg}$ $\mathrm{m}^{-2}$ (95\% confidence intervals; $6.0-7.3 \mathrm{~kg} \mathrm{~m}^{-2}$ ) beneath vehicle load bearing surfaces (e.g. roads, car parks, residential driveways) which had soil between 40 and $100 \mathrm{~cm}$ depth, and $13.5 \mathrm{~kg} \mathrm{~m}^{-2}$ (95\% confidence intervals; $12.3-14.9 \mathrm{~kg} \mathrm{~m}^{-2}$ ) under non-vehicle load bearing surfaces (e.g. footpaths, pavements/sidewalks) which had soil between 15 and $100 \mathrm{~cm}$ depth.

A comparison of soil $\mathrm{OC}$ density in urban soil with regional arable soils. As with the urban soils, the relationship between OC density and depth in arable soils was best described by a negative exponential function $\left(R^{2}=76 \%, F_{(1,47)}=152.5, p<0.001, \mathrm{y}=38.486\right.$ $( \pm 2.761$ S.E. $) e^{-0.0242( \pm 0.003 \text { S.E.) } \times)}$ (Fig. 2). Analysis of covariance established that the urban soils store significantly more OC than arable soils, at equivalent depths (Table 1). The relationship between soil OC density and depth reveals a storage value of $14.3 \mathrm{~kg} \mathrm{OC} \mathrm{m}^{-2}$ (95\% confidence intervals; $12.24-16.37 \mathrm{~kg} \mathrm{~m}^{-2}$ ) in arable soils to $100 \mathrm{~cm}$ depth, a value significantly lower than the

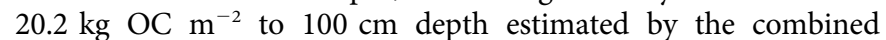
urban soil depth response curve (Fig. 2).

The city-wide OC budget. City-wide OC storage, exceeded 1.2 million tonnes across $73 \mathrm{~km}^{2}$, with approximately $69 \%, 13 \%$ and $18 \%$ stored in greenspace soil, capped soil (to $100 \mathrm{~cm}$ depth) and vegetation respectively (Fig. 3). This equates to $17.6 \mathrm{~kg} \mathrm{OC} \mathrm{m}^{-2}$ across the whole city area, $14.5 \mathrm{~kg} \mathrm{~m}^{-2}$ of which was found in soil, with the un-sampled $15 \%$ of the city under buildings assumed to hold

Table 1 Analysis of covariance of the effects of urban and rural land-cover/land-use and depth on soil organic carbon density

\begin{tabular}{lcrrr} 
& transformation & d.f. & F & P value \\
\hline Urban soils & & & & 0.105 \\
Factor: Land-cover (herbaceous or tree \& shrub or capped) & square root & 2,182 & 2.227 & $<0.001$ \\
Covariate: Depth (see Fig. 1) & & 1,182 & 164.918 & $<0.001$ \\
Urban versus rural soil & $\log _{10}$ & 1,232 & 20.893 & $<0.001$ \\
Factor: Land-use (urban or arable) & & 1,232 & 234.302 & \\
Covariate: Depth (see Fig. 2) & & &
\end{tabular}




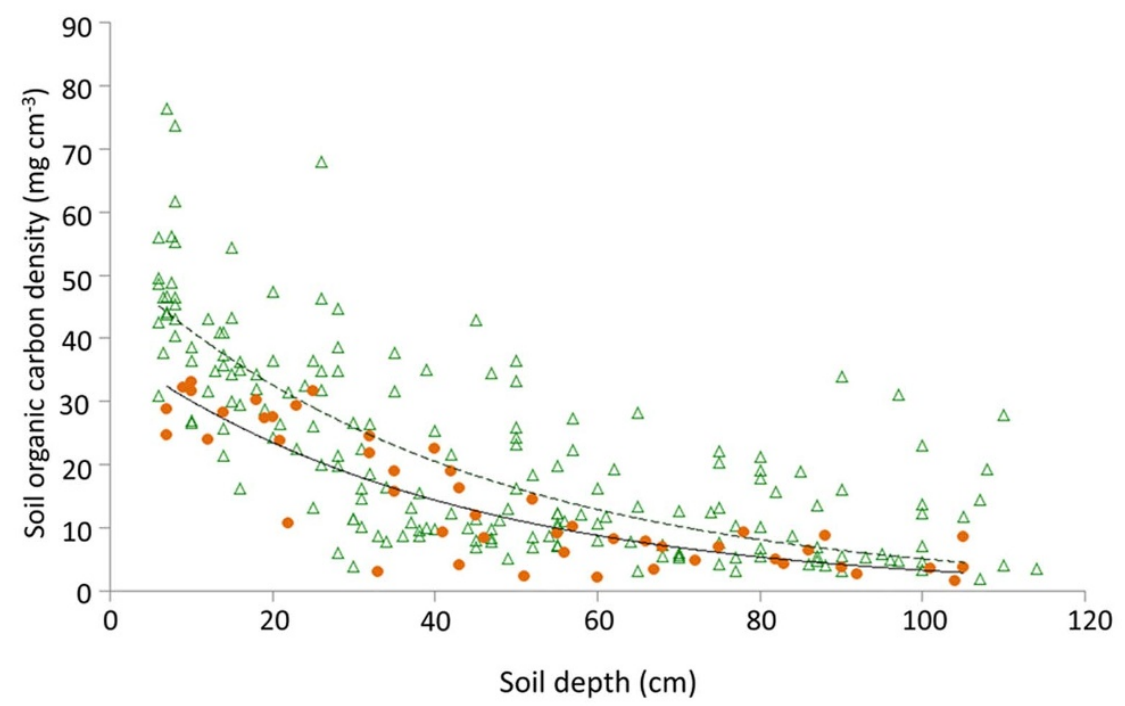

Figure 2 The relationship between soil organic carbon density and depth in urban and arable soils. Urban soils represented by open triangular data points $(\Delta)$ and continuous line of best fit; arable soils represented by open circular data points $(\bullet)$ and dashed line of best fit.

no OC (Fig. 3). Residential and non-residential land both stored

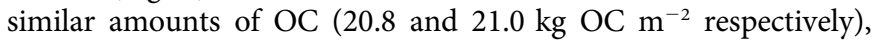
however the relative contributions from soil and vegetation varied considerably (Fig. 3). Furthermore, non-residential land made a much larger overall contribution than residential land to the excess of 1 million tonnes of OC found in the soils (Table 2), as a result of its greater areal extent (Table 3). In both residential and non-residential land (Fig. 3), greenspace soils contributed the largest proportion of OC to total storage ( $84 \%$ and $63 \%$ respectively), compared to soils beneath impervious surfaces (which contributed $12 \%$ of total OC stored in residential and $13 \%$ of total OC stored in non-residential land). The proportion of OC stored in vegetation was greater in nonresidential land, $23 \%$ of total storage, in contrast with the $4 \%$ contribution made by vegetation in residential land.

\section{Discussion}

Our results reveal that on a city-wide basis urban OC storage in soils and vegetation was $17.6 \mathrm{~kg} \mathrm{~m}^{-2}$ (to $100 \mathrm{~cm}$ depth) even though $15 \%$ of the city beneath buildings was assumed to store no OC. Soil OC storage across the entire urban area was far in excess of the values

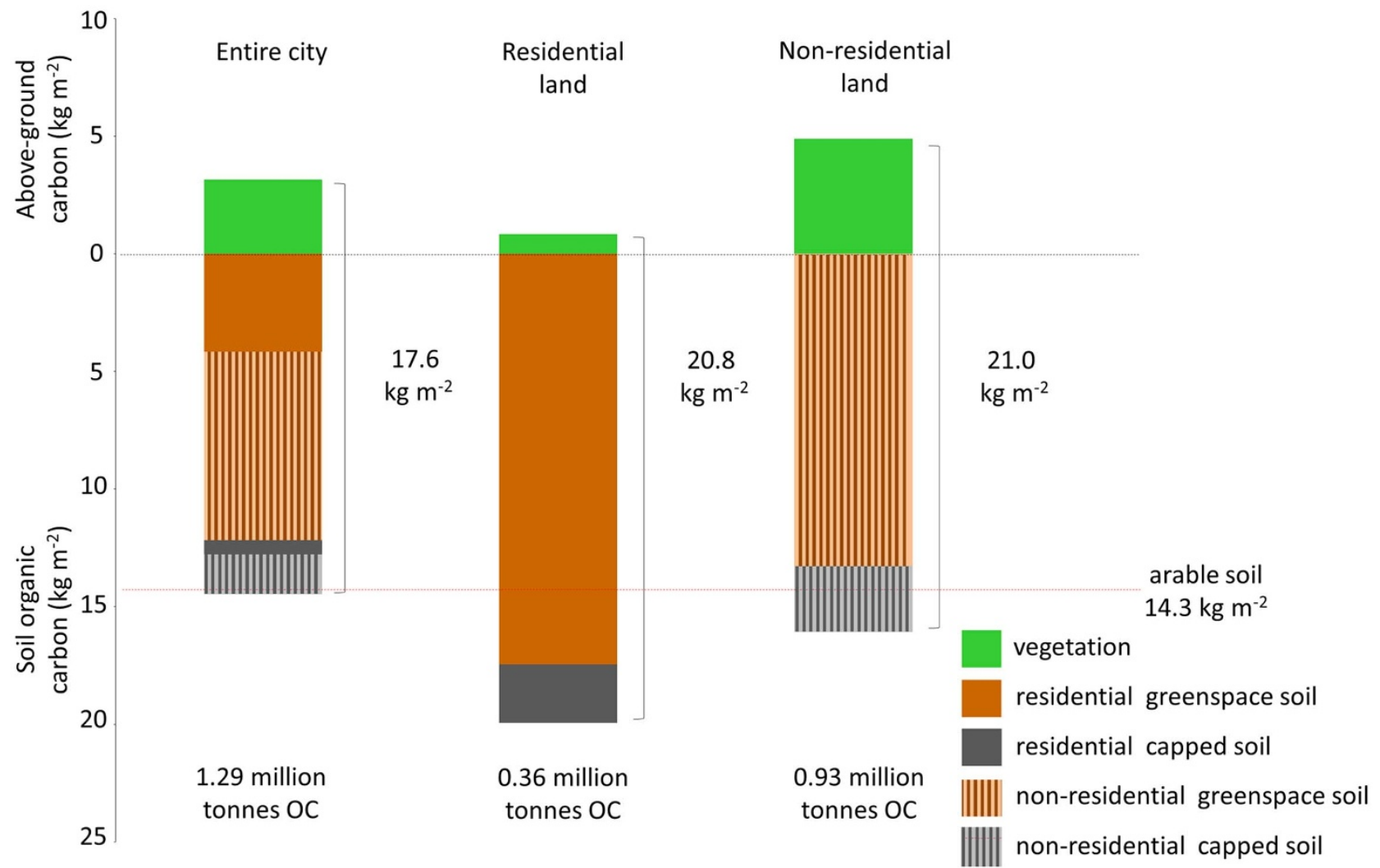

Figure 3 Organic carbon storage density across the entire city (including the area covered by buildings), and in residential and non-residential land (excluding the area covered by buildings). 


\begin{tabular}{|c|c|c|c|}
\hline Land-cover & Residential land & Non-residential land & Total \\
\hline Greenspace 0-21 cm & $\begin{array}{c}153,512 \\
(143157-163867)\end{array}$ & $\begin{array}{c}258,041 \\
(243,975-272,1071\end{array}$ & $\begin{array}{c}411,553 \\
(394,087-429.019)\end{array}$ \\
\hline Greenspace $21-100 \mathrm{~cm}$ & $\begin{array}{c}(143151,314 \\
(137,021-165,737)\end{array}$ & $\begin{array}{c}(243,4)-2924 \\
329,524 \\
(298,399-360,934)\end{array}$ & $\begin{array}{c}(394,887-429,019) \\
480,838 \\
(446,588-515,401)\end{array}$ \\
\hline Non-load bearing artificial surface $15-100 \mathrm{~cm}$ & $\begin{array}{c}14,851 \\
(13,444-16,258)\end{array}$ & $\begin{array}{c}85,404 \\
(77,313-93,495)\end{array}$ & $\begin{array}{c}100,256 \\
(92,043-108,468)\end{array}$ \\
\hline Load bearing artificial surface $40-100 \mathrm{~cm}$ & $\begin{array}{c}28,888 \\
(26,148-31,628)\end{array}$ & $\begin{array}{c}39,111 \\
(35,401-42,821)\end{array}$ & $\begin{array}{c}67,999 \\
(63,387-72,611)\end{array}$ \\
\hline Total soil organic carbon & $\begin{array}{c}345,565 \\
(330,649-366,585)\end{array}$ & $\begin{array}{c}712,080 \\
(676,784-747,628)\end{array}$ & $\begin{array}{c}1,060,646 \\
(1,021,062-1,100,500)\end{array}$ \\
\hline
\end{tabular}

used in England to estimate urban soil OC storage $\left(0 \mathrm{~kg} \mathrm{~m}^{-2}\right.$ for areas designated 'continuous urban fabric' and a mean of $6 \mathrm{~kg} \mathrm{~m}^{-2}$ for 'suburban' areas based on an assumption that these have half the OC of grasslands in the same region) ${ }^{3}$. Our findings reveal that the previously untested assumptions used to estimate OC storage in urban areas in the UK are insecure, and likely to lead to serious underestimates. In addition, OC storage in vegetation across the city was an order of magnitude greater than that estimated in the national inventory, reflecting limitations in the relatively low spatial resolution GIS-based methods used in the national studies when applied to urban areas which have many small patches of greenspaces ${ }^{32}$.

Previously, a lack of data has necessitated the assumption that soils beneath urban grey infrastructure are so functionally compromised that they are unable to store OC, with the exception of a study in the U.S.A., where measurements of OC concentrations in clean fill soil were used, as a proxy, to derive a storage estimate of $3.16 \mathrm{~kg} \mathrm{~m}^{-2}$ between 0 and $100 \mathrm{~cm}^{28}$. However, recent work in New York found soils beneath urban pavements at sites deemed suitable for tree planting stored $5.8 \mathrm{~kg}$ OC m $\mathrm{m}^{-2}$ between 0 and $100 \mathrm{~cm}$ depth, but this research found a reduced soil OC stock when compared to adjacent open spaces ${ }^{33}$. In Leicester soil OC density was not affected by surface cover (e.g. vegetated or capped); however storage was compromised by depth of soil excavation for the capping surface resulting in estimates of $6.7 \mathrm{~kg} \mathrm{OC} \mathrm{m}^{-2}(40-100 \mathrm{~cm}$ depth) beneath roads and other load bearing surfaces and $13.5 \mathrm{~kg}_{\mathrm{OC} \mathrm{m}}^{-2}$ (15-100 $\mathrm{cm}$ depth) beneath pavements and footpaths, the latter being considerably higher than the aforementioned values reported for soil under pavements in New York City ${ }^{33}$. This difference was particularly pronounced in the $45-60 \mathrm{~cm}$ depth interval, where the estimate of $0.6 \mathrm{~kg} \mathrm{OC} \mathrm{m}^{-2}$ in soil in the New York study was approximately a quarter of that found in Leicester between equivalent depths $(2.4 \mathrm{~kg}$ $\mathrm{m}^{-2}$ ), possibly reflecting a greater clay content, which stabilises OC, in the Leicester soils or climatic differences between the two cities.

The relationships presented for both urban and arable soils were best described by a negative exponential function, as is typical when investigating the vertical distribution of soil OC with depth ${ }^{34}$. Indeed, the relationship between soil depth and urban soil OC density conformed to that reported for many temperate ecosystems ${ }^{1,35-40}$. Proportionally, the amount of soil OC within the top $20 \mathrm{~cm}$ of the $100 \mathrm{~cm}$ urban soil depth profile was $42 \%$, which is consistent with the values reported for temperate grassland worldwide $(41 \%)^{1}$. This contrasts sharply to the common assumption that urban soils are functionally compromised ${ }^{41-43}$, with our data demonstrating for the first time that not only greenspace soils, but also those beneath impervious surface are able to store considerable amounts of OC to $100 \mathrm{~cm}$ depth at a city-wide scale.

As yet it is unclear whether the OC stocks in soils beneath impervious surfaces are essentially passive, and therefore a reflection of the OC present at the time of capping, or whether there is active turnover of OC in the soils. However, it is likely that both of these scenarios occur depending upon the type of capping and the extent of impervious surface. For example, the two categories of impervious surfaces we studied covered $4.36 \mathrm{~km}^{2}$ of residential land in Leicester, which will predominantly be patches of patio, garden path or residential driveway ${ }^{44,45}$. These surfaces generally cover small discrete areas within a mosaic of lawn, flowerbeds, and hedging, contrasting with the larger patches of impervious surface, such as major roads, within the city as a whole. Above-ground, the boundaries between vegetation in residential land and the discrete areas of impervious surface are clearly visible, however the soils underlying capped surfaces could be colonised by the root systems of lawn grasses and garden trees and shrubs. Therefore it is likely that below these smaller patches of impervious surface the soil remains active potentially accumulating soil OC.

Although the residential and non-residential land in Leicester stored a similar quantity of OC on a per unit area basis, the contribution of the soil and vegetation components to the budget varied between land ownership category (Fig. 3). This difference is likely to reflect distinct management practices in the two land ownership categories. Above-ground vegetation OC storage made a substantial contribution to the overall OC budget in non-residential land (23\%), due both to greater tree cover and the frequency of large trees ${ }^{32}$, whereas tree and shrub cover and size was lower in residential land. Residential greenspace soil OC stock per unit area was higher than in the non-residential greenspace (Fig. 3), possibly reflecting management inputs such as compost, mulches and organic fertilizers ${ }^{46,47}$.

Soil OC storage in arable soils to $100 \mathrm{~cm}$ depth $\left(14.3 \mathrm{~kg} \mathrm{~m}^{-2}\right)$ was significantly lower than that in urban soils $\left(20.2 \mathrm{~kg} \mathrm{~m}^{-2}\right)$. This serves as a reminder of the loss of soil OC from arable land as a result of erosion of carbon-rich topsoil and increased carbon oxidation associated with tillage, and modern agricultural practices such as greater fertilizer use ${ }^{48-50}$. As the city of Leicester has developed it has encroached predominantly onto established agricultural land, although the primeval successional climax habitat for the region would have been deciduous woodland. In the UK the soil OC storage value for woodland in the national inventory ${ }^{3}$ ranges regionally from 17 to $37 \mathrm{~kg} \mathrm{~m}^{-2}$ with a mean of $25 \mathrm{~kg} \mathrm{~m}^{-2}$. The urban soil OC storage value for Leicester falls within this range. However, when urban soil OC storage was calculated over the entire city area (where soils beneath buildings, covering $15 \%$ of the urban area, were assumed to hold no OC, and the soil OC removed by excavation beneath impervious surfaces, covering a further $27 \%$ of the city, was accounted for) there was no difference in overall storage between urban (14.5 $\mathrm{kg} \mathrm{m}^{-2}$ ) and arable land (14.3 $\mathrm{kg} \mathrm{m}^{-2}$ ) (Fig. 3).

Our estimate for soil OC storage, on a per unit area basis, for arable soils was consistent with the values used in the national soil OC inventory for the $\mathrm{UK}^{3}$. However, our research reveals a stark contrast between city-wide OC storage in Leicester and the values used in national OC storage inventories for urban areas. In total, England is reported to store $1740 \mathrm{Tg}$ OC in soil to $100 \mathrm{~cm}$ depth, approximately $3 \%$ of which has been estimated to be held within suburban (or garden) land ${ }^{3}$, which has a national mean value of $6 \mathrm{~kg} \mathrm{OC} \mathrm{m}^{-2}$, a 


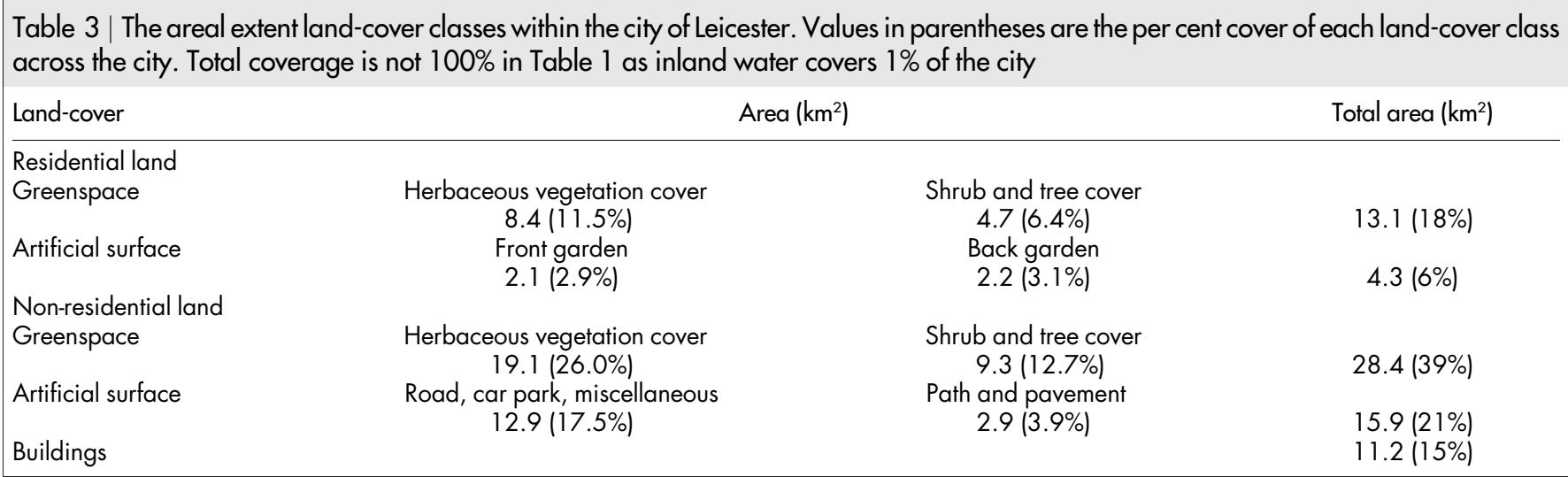

figure considerably lower than that reported for Leicester $(14.5 \mathrm{~kg}$

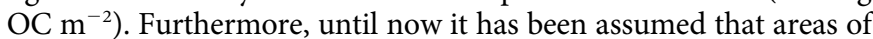
'continuous urban fabric' store no $\mathrm{OC}^{3}$, an assumption clearly invalidated by our measurements and findings.

Areas of 'continuous urban fabric' not only contain a substantial area of greenspace in patches within a mosaic of built-over land $\mathrm{d}^{32}$, but also hold a considerable amount of soil OC beneath the impervious surface which may cover a substantial proportion of this land-use category. The conservative and previously untested assumptions that have been applied to English national OC inventories ${ }^{3,23}$ are by no means unique as similar assumptions about $\mathrm{OC}$ storage within urban areas have been applied to other countrie ${ }^{22,24,25}$. It is now apparent that these assumptions are not robust and have the potential to contribute to significant underestimation of OC stocks in inventories at national scales. It has been estimated that it would require the monitoring of 96,000 sites across the whole of England and Wales to detect a $1 \%$ change in national soil OC stocks ${ }^{51}$. However, our findings suggest that resolving the uncertainty associated with the contribution of urban soils to national OC stocks would achieve a greater improvement in estimates with a smaller sampling effort. This highlights the urgent need to extend the measurement of OC stocks to other cities and countries, especially in Western Europe, to improve the accuracy of national and global budgets of this vital ecosystem service.

\section{Methods}

Study area. Our study focussed on Leicester, a typical mid-sized U.K. city located, in the East Midlands of England $\left(52^{\circ} 38^{\prime} \mathrm{N}, 1^{\circ} 08 \mathrm{~W}\right.$ ). Covering approximately $73 \mathrm{~km}^{2}$ (as defined by the unitary authority boundary), buildings comprise more than $15 \%$ of the city area, impervious surfaces (including roads, patios and pavements etc.) over $27 \%$, and greenspace coverage exceeds $56 \%$ (Table 3 ). The city has a population of approximately $300,000^{52}$. Soil types within the region are dominated by deep clays, deep loam and seasonally wet deep clays and loam, according to the National Soil Map for England and Wales produced by Cranfield University. The region has a temperate climate, receiving $606 \mathrm{~mm}$ of precipitation each year and average annual daily minimum and maximum temperatures of $5.8^{\circ} \mathrm{C}$ and $13.5^{\circ} \mathrm{C}$ respectively ${ }^{53}$. The dominant land-use in the region is agriculture, $74 \%$ of which is arable.

Soil and vegetation sampling. The land-cover characteristics of the study city (Leicester, England) were determined using a Geographic Information System (GIS), comprised of the high resolution $\left(0.25 \mathrm{~m}^{2}\right)$ vector LandBase and Mastermap datasets, which; divided the city into seven land-cover classes (artificial surface, buildings, inland water, herbaceous vegetation, trees, tall shrubs and shrubs), and identified residential and non-residential land respectively $y^{54}$. Sampling locations were randomly generated within the GIS, throughout the greenspace land-cover strata defined by vegetation height, in residential and non-residential areas.

A total of 136 sites were sampled to measure top soil OC to $21 \mathrm{~cm}$ depth. At each site, four replicate soil samples were taken at three depths $(0-7,7-14,14-21 \mathrm{~cm})$ where possible, using a bulk density corer (Eijkelkamp, Holland) ${ }^{55}$. A GIS was used randomly to select 25 locations within publicly accessible greenspace, where samples were taken in 14 herbaceous and 11 shrub, tall shrub and tree sites managed by Leicester City Council to $100 \mathrm{~cm}$ depth. Soils were not sampled to $100 \mathrm{~cm}$ depth in residential greenspace due to the risk of intercepting any buried utility infrastructur $^{56}$. At each of these sites a soil profile core was taken in $7 \mathrm{~cm}$ sections, however as soil depth increased it was often necessary to widen the existing soil core profile slightly, using an auger designed specifically to aid soil sampling with the bulk density corer. As a consequence, several centimetres of soil were sometimes removed from the base of the soil profile before removal of the next core, and therefore soil depths in the $100 \mathrm{~cm}$ profile were not always taken at regular $7 \mathrm{~cm}$ intervals. None of these deeper samples encountered buried artificial surfaces, imported material (such as gravel, commonly used to infill after excavation) or bedrock, but in some cases it was not possible to sample to the full $100 \mathrm{~cm}$ depth because of roots or stones. Soils under grey infrastructure are normally inaccessible, but permission was granted by Leicester City Council and several utility companies to sample at 17 excavation sites across the city, at a range of depths, providing 127 soil samples in total.

Soil samples were taken within arable fields, as crop production is the dominant form of agriculture in the region, from within a $7.5 \mathrm{~km}$ buffer zone surrounding the unitary authority boundary of Leicester. Within each of the randomly selected fields $(\mathrm{n}=6)$ soils were sampled at approximately $7 \mathrm{~cm}$ intervals to a depth of approximately $100 \mathrm{~cm}$

A vegetation sampling strategy, stratified in a GIS by land-ownership (Mastermap) and vegetation type (LandBase), was produced and vegetation was measured (at 347 sites) across the city to produce a city-wide inventory of vegetation $\mathrm{OC}$ in trees, shrubs, tall shrubs and herbaceous vegetation in residential and non-residential $\operatorname{land}^{32}$. At each of the sample points the proportion of ground covered by herbaceous vegetation, woody vegetation, bare soil, inland water, artificial surface, or buildings was estimated within a $5 \times 5 \mathrm{~m}$ quadrat ${ }^{32}$. Any trees within the quadrat were identified to species where possible or genus and measurement was taken of crown height and diameter at breast height $(1.3 \mathrm{~m})$, in order to estimate tree biomass using allometric equations published in the literature ${ }^{32}$.

Soil preparation and analysis. Individual soil samples were dried at $105^{\circ} \mathrm{C}$ for 24 hours and then weighed. The soil sample was subsequently homogenized into a fine powder in an agate ball-mill (Pulverisette, Fritsch, Idar-Oberstein Germany). Each ball-milled sample was then passed through a $1 \mathrm{~mm}$ sieve (to remove any stones, or anthropogenic debris that were left intact during milling) and re-dried at $105^{\circ} \mathrm{C}$. Any material greater than $1 \mathrm{~mm}$ in diameter was retained, weighed, and removed from the initial dried sample weight to calculate fine earth soil bulk density $\left(\mathrm{g} \mathrm{cm}^{-3}\right)^{55}$ The method of soil sample preparation differed from the conventional method, whereby samples are air dried then passed through a $2 \mathrm{~mm}$ sieve prior to analysis ${ }^{29}$, however a method validation comparing the method detailed above and the conventional method demonstrated that the two methods are equivalent (see supplementary material).

In our analyses ball-milled and $<1 \mathrm{~mm}$ sieved soil samples were analysed in duplicate for total carbon (TC) concentration in a CN analyser (Vario EL Cube, Elementar, Hanau, Germany). Inorganic carbon (IC) was removed from soil samples by adding $10 \mathrm{ml} \mathrm{HCl}(5.7 \mathrm{M})$ to $2.5 \mathrm{~g}$ soil ${ }^{29}$. Samples were centrifuged at $1800 \mathrm{~g}$ for 10 minutes, the supernatant was removed and the soils were dried at $105^{\circ} \mathrm{C}$ and CN analysis used to determine soil OC concentration.

Soil samples taken from directly below asphalt concrete were analysed using loss on ignition, as initial CN analysis revealed high OC concentrations (mean $=162.9 \mathrm{mg}$ $\mathrm{g}^{-1} \pm 28.9 \mathrm{mg} \mathrm{g}^{-1}($ S.E. $), \mathrm{n}=5$ ). The high soil OC concentrations were attributed to soil contamination with bitumen. The standard loss on ignition temperature of $450^{\circ} \mathrm{C}$ was reduced to $340^{\circ} \mathrm{C}$, as this temperature that does not volatilize bitumen ${ }^{57}$, the main constituents of which have boiling points above $500^{\circ} \mathrm{C}^{57}$ but it does oxidise the majority of $\mathrm{OC}^{29}$. This is a conservative approach that will tend to underestimate rather than overestimate organic carbon in this rather small group of samples which present significant challenges for accurate OC measurements.

City-wide carbon budget and statistical analysis. The relationships between soil OC and depth were established using regression analysis and these were used to model soil OC storage $\left(\mathrm{kg} \mathrm{m}^{-2}\right)$. The effect of land-cover or land-use on soil OC density over the 0-100 $\mathrm{cm}$ depth range sampled was analysed using ANCOVA in PASW (version $18)^{58}$. Data were checked for normality and homogeneity, and were transformed using $\log _{10}$ or square root transformation, where test assumptions were not met.

Soil OC storage for $0-21 \mathrm{~cm}$ depth in urban greenspace was calculated from mean values obtained by measurements at 136 sites across the city that were stratified in a 
GIS by residential and non-residential land ownership class. The estimation of soil OC stocks in urban greenspace from $21-100 \mathrm{~cm}$ depth was obtained using a best-fit model for urban soil samples describing the relationship between depth and soil OC, which was a negative exponential function.

The urban soil depth curve function was also used to derive soil OC values for land covered with impervious surfaces (excluding buildings). Impervious surface was classified into two categories, based on whether or not they were vehicle load bearing, as this determined the depth of soil excavation prior to surface construction: (a) roads, car parks, residential driveways at the front of dwellings and any miscellaneous impervious surface (mean excavation depth of $40 \mathrm{~cm}( \pm 7 \mathrm{~cm}, \mathrm{n}=12)$ ), and; (b) footpaths, pavements and areas covered by impervious surfaces to the rear of dwellings (mean excavation depth of $15 \mathrm{~cm}( \pm 3 \mathrm{~cm}, \mathrm{n}=5)$ ). The soil OC storage values $\left(\mathrm{kg} \mathrm{m}^{-2}\right)$ within each impervious surface category (load bearing: $40-100 \mathrm{~cm}$ soil depth; non-load bearing: $15-100 \mathrm{~cm}$ soil depth) and greenspace $(0-100 \mathrm{~cm}$ soil depth) land-cover category were multiplied by the areal extent of each individual land-cover class (Table 3 ) to estimate city-wide soil OC storage. It was assumed that no soil OC was stored beneath buildings, which covers an area of approximately $15 \%$ of the city (Table 3 ). The soil OC data was combined with recently reported vegetation OC stocks for the city of Leicester ${ }^{32}$.

1. Jobbagy, E. G. \& Jackson, R. B. The vertical distribution of soil organic carbon and its relation to climate and vegetation. Ecol. Appl. 10, 423-436 (2000).

2. Guo, L. B. \& Gifford, R. M. Soil carbon stocks and land use change: a meta analysis. Glob. Change Biol. 8, 345-360 (2002)

3. Bradley, R. I. et al. A soil carbon and land use database for the United Kingdom. Soil Use Manage. 21, 363-369 (2005).

4. Batjes, N. H. Total carbon and nitrogen in soils of the world. Eur. J. Soil Sci. 47, 151-163 (1996).

5. Falkowski et al. The global carbon cycle: a test of our knowledge of earth as a system. Science 290, 291-296 (2000).

6. Houghton, R. A. Revised estimates of the annual net flux of carbon to the atmosphere from changes in land use and land management 1850-2000. Tellus 55B, 378-390 (2003)

7. Vitousek, P. M., Mooney, H. A., Lubchenco, J. \& Melillo, J. M. Human domination of Earth's ecosystems. Science 227, 494-499 (1997).

8. Smith, P. Land use change and soil carbon dynamics. Nutr. Cycl. Agroecosys 81, 169-178 (2008).

9. United Nations. World urbanization prospects: the 2007 revision. (United Nations, 2008).

10. Meyer, W. B. \& Turner II, B. L. Human population growth and global land-use/ cover change. Annu. Rev. Ecol. Syst. 23, 39-61 (1992).

11. Antrop, M. Changing patterns in the urbanised countryside of Western Europe. Landscape Ecol. 15, 257-270 (2000).

12. McKinney, M. L. Urbanization, biodiversity, and conservation. BioScience 52, 883-890 (2002).

13. Hansen, A. J. et al. Effects of exurban development on biodiversity: patterns, mechanisms and research needs. Ecol. Appl. 15, 1893-1905 (2005)

14. EEA. Urban sprawl in Europe. The ignored challenge. Report No. 10. (European Environment Agency, 2006).

15. White, E. M., Morzillo, A. T. \& Alig, R. J. Past and projected rural land conversion in the US at state, regional and national levels. Landscape Urban Plan. 89, 37-48 (2009).

16. Gaston, K. J. Urbanisation. In: Urban Ecology (Ed. Gaston, K. J.), pp. 10-34 (Cambridge University Press, 2010).

17. Dallimer, M. et al. Temporal changes in greenspace in a highly urbanised region. Biology Lett. 7, 763-766 (2011).

18. Scalenghe, R. \& Marsan, F. A. The anthropogenic sealing of soil in urban areas Landscape Urban Plan 90, 1-10 (2009).

19. Fuller, R. A. \& Gaston, K. J. The scaling of green coverage in European cities Biology Lett. 5, 352-355 (2009).

20. Elvidge, C. D. et al. Global distribution and density of constructed impervious surfaces. Sensors 7, 1962-1979 (2007).

21. Bibby, P. Land use change in Britain. Land Use Policy 26S, S2-S13 (2009).

22. Arrouays, D., Deslais, W. \& Badeau, V. The carbon content of topsoil and its geographical distribution in France. Soil Use Manage 17, 7-11 (2001).

23. Milne, R. \& Brown, T. A. Carbon in the vegetation and soils of Great Britain. J. Environ. Manage. 49, 413-433 (1997).

24. Cruikshank, M. M., Tomlinson, R. W., Devine, P. M. \& Milne, R. Carbon in the vegetation and soils of Northern Ireland. P. Roy. Irish Acad. B 98B, 9-21 (1998).

25. Xu, X., Lui, W., Zhang, C. \& Kiely, G. Estimation of SOC stock and its spatial distribution in the Republic of Ireland. Soil Use Manag 27, 156-162 (2011).

26. Nowak, D. J. \& Crane, D. E. Carbon storage and sequestration by urban trees in the USA. Environ. Pollut. 116, 381-389 (2002).

27. Kaye, J. P., Groffman, P. M., Grimm, N. B., Baker, L. A. \& Pouyat, R. V. A distinct urban biogeochemistry? Trends Ecol. Evol. 21, 195-199 (2006)

28. Pouyat, R. V., Yesilonis, I. D. \& Nowak, D. J. Carbon storage by urban soils in the United States. J. Environ. Qual. 35, 1566-1575 (2006)

29. Rawlins, B. G. et al. Methods for estimating soil organic carbon and their application to surveys of UK urban areas. Soil Use Manage 24, 47-59 (2008).

30. Churkina, G., Brown, D. G. \& Keoleian, G. Carbon stored in human settlements: the conterminous United States. Glob. Change Biol. 16, 135-143 (2010).
31. Pouyat, R. V., Yesilonis, I. D. \& Golubiewski, N. E. A comparison of soil organic carbon stocks between residential turf grass and native soil. Urban Ecosystems 12, 45-62 (2009).

32. Davies, Z. G., Edmondson, J. L., Heinemeyer, A., Leake, J. R. \& Gaston, K. J. Mapping an urban ecosystem service: quantifying above-ground carbon storage at a city-wide scale. J. Appl. Ecol. 48, 1125-1134 (2011).

33. Raciti, S. M., Hutrya, L. R. \& Finzi, A. C. Depleted soil carbon and nitrogen pools beneath impervious surfaces. Environ. Pollut. 164, 248-251 (2012).

34. Meersmans, J. et al. Changes in organic carbon distribution with depth in agricultural soils in northern Belgium, 1960-2006. Glob. Change Biol. 21, 2379-2750 (2009).

35. Jackson, R. B., Banner, J. L., Jobbagy, E. G., Pockman, W. T. \& Wall, D. H. Ecosystem carbon loss with woody plant invasion. Nature 418, 623-626 (2002).

36. Rumpel, C., Kogel-Knaber, I. \& Bruhn, F. Vertical distribution, age, and chemical composition of organic carbon in two forest soils of different pedogenesis. Organic Chemistry 33, 1131-1142 (2002).

37. Castellazi, M. S., Brookes, P. C. \& Jenkinson, D. S. Distribution of microbial biomass down soil profiles under regenerating woodland. Soil Biol. Biochem 36 1485-1489 (2004).

38. Groffman, P. M. et al. Land use context and natural soil controls on plant community composition and soil nitrogen and carbon dynamics in urban and rural forests. Forest Ecol. Manag 236, 177-192 (2006).

39. Fontaine, S. et al. Stability of organic carbon in deep soil layers controlled by fresh carbon supply. Nature 450, 277-281 (2007)

40. Kramer, C. \& Gleixner, G. Soil organic matter in soil depth profiles: Distinct carbon preferences of microbial groups during carbon transformation. Soil Biol. Biochem. 40, 425-433 (2008).

41. Jim, C. Y. Urban soil characteristics and limitations for landscape planting in Hong Kong. Landscape Urban Plan 40, 235-249 (1998).

42. Lorenz, K. \& Kandeler, E. Biochemical characterization of urban soil profiles from Stuttgart, Germany. Soil Biol. Biochem 37, 1373-1385 (2005).

43. Pitt, R., Chen, S., Clark, S. E., Swenson, J. \& Ong, C. K. Compaction's impacts on urban storm-water infiltration. Journal of Irrigation and Drainage Engineering 134, 652-658 (2008)

44. Smith, R. M., Gaston, K. J., Warren, P. H. \& Thompson, K. Urban domestic gardens (V): relationships between land-cover composition, housing and landscape. Landscape Ecol. 20, 235-253 (2005).

45. Loram, A., Warren, P. H. \& Gaston, K. Urban domestic gardens (XIV): the characteristics of gardens in five cities. Environ. Manage 42, 361-376 (2008)

46. Robbins, P. \& Birkinholtz, T. Turfgrass revolution: measuring the expansion of the American lawn. Land Use Policy 20, 181-194 (2003).

47. Osmond, D. L. \& Hardy, D. H. Characterization of turf practices in five North Carolina communities. J. Environ. Qual. 33, 565-575 (2004).

48. Smith, P. et al. Carbon sequestration potential in European croplands has been overestimated. Global Change Biol 11, 2153-2163 (2005).

49. Ciais, P. et al. The European carbon balance. Part 2: croplands. Global Change Biol. 16, 1409-1428 (2010).

50. Sun, B., Halett, P. D., Caul, S., Daniell, T. J. \& Hopkins, D. Distribution of soil carbon and microbial biomass in arable soils under different tillage regimes. Plant Soil. 338, 17-25 (2011)

51. Saby, N. P. et al. Will European soil-monitoring networks be able to detect changes in topsoil organic carbon content? Global Change Biol 14, 2432-2442 (2008).

52. Leicester City Council. http://www.leicester.gov.uk/your-council-services/ council-and-democracy/city-statistics/ (last accessed Dec 2009). (2009).

53. Met Office. http://www.metoffice.gov.uk/climate/uk/averages/ (last accessed Dec 2009). (2009).

54. Murray, K. J. \& Sheill, D. A new geographic information framework for Great Britain. Photogramm. Eng. Rem. S. 69, 1175-1182 (2003).

55. Edmondson, J. L., Davies, Z. G., McCormack, S. A., Gaston, K. J. \& Leake, J. R. Are soils in urban ecosystems compacted? A city-wide analysis. Biology Lett. 23 771-774 (2011).

56. Lehmann, A. \& Stahr, K. Nature and significance of anthropogenic urban soil. J. Soils Sediments 7, 247-260 (2007).

57. Dettman, H., Inman, A., Salmon, S., Scott, K. \& Fuhr, B. Chemical characterization of GPC fractions of Athabasca bitumen asphaltenes isolated before and after thermal treatment. Energy and Fuels 19, 1399-1404 (2005).

58. Field, A. Discovering statistics using SPSS. $3^{\text {rd }}$ Edition (Sage Publications Ltd., 2009).

\section{Acknowledgements}

This work was supported by EPSRC grant EP/F007604/1 to the $4 \mathrm{M}$ consortium: Measurement, Modelling, Mapping and Management: an Evidence Based Methodology for Understanding and Shrinking the Urban Carbon Footprint. The consortium has five U.K. partners: Loughborough University, De Montfort University, Newcastle University, University of Sheffield and University of Exeter. Infoterra provided access to LandBase; MasterMap data were supplied by Ordnance Survey. The soil type data within Leicester were provided by Soils Data ${ }^{\circledR}$ Cranfield University (NSRI) and for the Controller of HMSO 2012. We thank Sarah McCormack and Jonathan Potter for technical assistance. We gratefully acknowledge Leicester City Council, the utility companies and the householders who granted access to their properties. 


\section{Author contributions}

J.L.E., Z.G.D., K.J.G. and J.R.L. designed the study. J.L.E. conducted the soil survey. J.L.E., Z.G.D. and N.M. analysed the data. J.L.E. and J.R.L. wrote the manuscript in collaboration with all authors.

\section{Additional information}

Supplementary information accompanies this paper at http://www.nature.com/ scientificreports
Competing financial interests: The authors declare no competing financial interests.

License: This work is licensed under a Creative Commons

Attribution-NonCommercial-NoDerivs 3.0 Unported License. To view a copy of this license, visit http://creativecommons.org/licenses/by-nc-nd/3.0/

How to cite this article: Edmondson, J.L., Davies, Z.G., McHugh, N., Gaston, K.J. \& Leake, J.R. Organic carbon hidden in urban ecosystems. Sci. Rep. 2, 963; DOI:10.1038/srep00963 (2012). 